\title{
Recurrent Childhood T Acute Lymphoblastic Leukemia
}

National Cancer Institute

\section{Source}

National Cancer Institute. Recurrent Childhood T Acute Lymphoblastic Leukemia. NCI

Thesaurus. Code C131875.

The reemergence of $\mathrm{T}$ acute lymphoblastic leukemia in childhood after a period of remission. 